\title{
CFD modeling of the atmospheric boundary layer in short test section wind tunnel
}

\author{
Yassen El-Sayed Yassen, Ahmed Sharaf Abdelhamed \\ Mechanical Power Engineering, Faculty of Engineering, Port Said University, Port Said, Egypt \\ Email address: \\ y_yassen70@yahoo.com (Y. El-Sayed Yassen), sh_ahmed99@yahoo.com (A. S. Abdelhamed)
}

\section{To cite this article:}

Yassen El-Sayed Yassen, Ahmed Sharaf Abdelhamed. CFD Modeling of the Atmospheric Boundary Layer in Short Test Section Wind Tunnel. American Journal of Aerospace Engineering. Special Issue: Hands-on Learning Technique for Multidisciplinary Engineering Education.

Vol. 2, No. 1-1, 2015, pp. 38-46. doi: 10.11648/j.ajae.s.2015020101.14

\begin{abstract}
The aim of this paper is to provide a contribution to algorithms for the numerical simulation of the atmospheric boundary layer (ABL) in short test section wind tunnel, with the lowest pressure loss possible, for large Re, similar to the high values observed in nature. Different turbulent models have been examined for their relative suitability for the atmospheric boundary layer airflow with and without the implementation of buoyancy effects with modified turbulence model constants for the atmosphere. Validation of turbulent models through comparison with wind tunnel experiments is essential for practical applications. It has been observed that the $k-\varepsilon$ model is most suitable tool for generation of an ABL in short-chamber wind tunnel. A comparison has been made with the available experimental data, from literature, and the predicted CFD values are very close to the corresponding experimental measurements. The simulation results show the importance of turbulence model constant $\left(C_{\mu}\right)$, the non-uniform velocity and turbulence intensity profiles. Also, the significance of $y^{+}$for consistent assessment is confirmed. However, it has been found that the buoyancy force makes significant change in boundary layer thickness without a major impact on computation time.
\end{abstract}

Keywords: Atmospheric Boundary Layer (ABL), Buoyancy Effect, Turbulence Models, Short Test Section Wind Tunnel, Numerical Simulation, Non-Uniform Velocity

\section{Introduction}

It would be possible to obtain an appropriate scale of the natural wind structure by covering a considerable length of the wind tunnel's floor with a material of suitable roughness $[1,2]$. However, the disadvantage of this process is that it requires a length of about $25 \mathrm{~m}$ to form a BL with 60 to $120 \mathrm{~cm}$ height, which is possible only in tunnels with a long test chamber [3]. Thus, improved techniques for reproduction of the main characteristics of natural winds, as well as the formation of the atmospheric boundary layer (ABL), are needed. These techniques will permit shorter test chambers, so that existing aeronautical tunnels could be used for atmospheric simulations of meteorological interest, with the advantage of flow control and improved data collection [4]. The several studies using the wind tunnel for simulating the characteristics and behavior of the atmosphere can be found in Refs. [5-9]. The accurate computational fluid dynamic (CFD) simulation of the ABL is becoming increasingly important. CFD is a tool which is increasingly being used to study a wide variety of processes in the $\mathrm{ABL}$, where its accurate modeling is an imperative precondition in computational wind engineering. The application of CFD to study atmospheric dispersion processes in the lower part of the ABL has become an important research subject. Validation is an essential aspect of this research and several comparative studies between CFD and wind tunnel or field measurements have been performed, e.g. [10-13]. In all of these publications, the intermittent nature of the dispersion process in the wind tunnel and field measurements as opposed to the Reynolds Averaged Navier -Stokes (RANS) solution of the CFD simulations is indicated as a reason for the observed discrepancies. These discrepancies could be reported as inaccuracies in the boundary conditions for the flow or the pollutant source and the underestimation of the turbulence kinetic energy $[14,15]$. The standard $k-\varepsilon$ turbulence model, widely employed in the simulation of the ABL due to the availability of appropriate boundary conditions and meteorological data [16-21], will serve as the starting point in investigating of the $\mathrm{ABL}$ under the influence of surface heat flux. The re-normalization group (RNG) $k-\varepsilon$ model which 
renormalizes the Navier-Stokes equations to account for small-scale turbulence [22]. While the realizable $k-\varepsilon$ model contains a new transport equation for the turbulent kinetic energy dissipation rate $(\varepsilon)$ and also, turbulence model constant $\left(C_{\mu}\right)$. These are expressed as a function of mean flow and turbulence properties rather than assumed to be constant $[23,24]$. Other two-equation RANS models are also available, like the $k-\omega$ model where the transport equations are the turbulent kinetic energy $(k)$ and the specific dissipation rate $(\omega)$. These models have been shown to perform much better than $k-\varepsilon$ models in adverse pressure gradients and therefore in predicting separation, but are very sensitive to free-stream/inlet conditions $[23,25]$. A compromise between the advantages of the $k-\varepsilon$ and $k$ - $\omega$ models is the shear stress transport (SST) $k-\omega$ model which employs the $k$ - $\omega$ model near the surface and the $k$ - $\varepsilon$ model in the free shear layers through the use of a blending function. Good performance of the SST $k$ - $\omega$ model for ABL flow around blunt bodies has been shown [26]. The SST k- $\omega$ model has also been adopted for detached eddy simulation (DES) turbulence models which combine the features of RANS simulation in part of the flow and large eddy simulation (LES) in the separated regions. However, these models solve the unsteady transport equations and are still significantly more computationally expensive than the steady RANS models [23]. Furthermore, the effect of flow in three dimensions over dunes has also been investigated in various studies, which include wind tunnel tests and CFD $[27,28]$. Most studies to date have focused on simulation of the neutral ABL, where buoyancy effects have mostly been ignored or modeled using a Boussinesq type approach [29]. CFD seems to be the obvious route to quantify these effects, which could make a new contribution to understanding the behavior of the flow fields in short test-section wind tunnel.

The objective of this research is to optimize the flow in the shortest possible extension of the wind tunnel, with the lowest pressure loss possible leading to formation of the ABL and obtain a large Re; similar to the high values observed in nature. Different turbulent models using ANSYS- Fluent14 have been examined for their relative suitability for the atmospheric boundary layer airflow with and without the implementation of buoyancy effects with modified turbulence model constants for the atmosphere. A typical CFD simulation is created in five steps. First, a model of the fluid region is sketched and any solid regions that might be present are defined. Thereafter, a mesh is applied to the sketch. Fluent uses finite-volume methods when calculating the flow field variables, with the mesh elements as the finite volumes. This means that the size of the mesh and the location of its elements determine where the flow field variables are evaluated. Hence, a fine mesh is needed where the flow is changing rapidly, while a coarser mesh can be used at locations in the model where the flow is uniform. The third step is to define the boundary and initial conditions of the problem as well as turbulence models. Then, the numerical calculations can commence, which form the fourth step. Fluent mostly uses second-order accurate numerical methods when evaluating the Navier-Stokes equations, together with various models when calculating for example the turbulence of the flow.

\section{Numerical Simulation of the ABL}

\subsection{Using the Wall Function with a Uniform (Constant) Inlet Velocity}

CFD simulations provide a way of predicting the behavior of a fluid without having to perform any experiments, and changes in the problem setup are easily made.

CFD codes employing RANS turbulence generally model the flow under turbulent conditions near walls using a wall function, providing that the flow velocity (constant) at the inlet is chosen to be the mean wind velocity of the wind profile [16]. The roughness of these surfaces is often expressed in terms of the equivalent wall roughness height $k_{s}[18,19]$. For the consistent and accurate application of the law of the wall, the dimensionless wall distance $y^{+}$would be in the range of 30 and less 500 [30] , placing a limit on the position of the first grid node from the wall, $z_{p}$.

\subsection{Using the Roughness Length with Friction Velocity (Non-Uniform Inlet Velocity)}

The inlet boundary profile is function of friction velocity $u *$ and the roughness length $z_{o}$. The logarithmic velocity profile law is given by [31]:

$$
u=\frac{u^{*}}{\kappa} \ln \left(\frac{z+z_{0}}{z_{0}}\right)
$$

Or the more simplified version, the power law:

$$
u=u *\left(\frac{z}{z_{0}}\right)^{\alpha}
$$

For $\alpha=1 / 7$ for flow of comparatively low Reynolds numbers. The turbulent kinetic energy $k$ can be derived from equations available in the literature [32], for simplicity

$$
k=\frac{u^{*^{2}}}{\sqrt{C_{\mu}}}
$$

An equation for the turbulent dissipation rate $\varepsilon$ is also available in the literature [33]:

$$
\varepsilon=\frac{u^{* 3}}{\kappa\left(z+z_{o}\right)}
$$

For the simulated case, the profile at the outlet boundary has exactly the expected profile.

\subsection{Using the Effects of Buoyancy on Turbulence in the $k-\varepsilon$ Models}

When a non-zero gravity field and temperature gradient are present simultaneously, the $k-\varepsilon$ models in ANSYS FLUENT 14 account for the generation of $k$ due to buoyancy $G_{b}$, and the corresponding contribution to the production of $\varepsilon$ [23].

$$
\int_{A} \rho k u_{i} n_{i} d A=\int_{A}\left(\mu+\frac{\mu_{t}}{\sigma_{k}}\right) \frac{\partial k}{\partial x_{i}} n_{i} d A+\int_{V}\left[G_{k}+G_{b}-\rho \varepsilon-Y_{m}\right] d V
$$


and

$$
\left.\int_{A} \rho \varepsilon u_{i} n_{i} d A=\int_{A}\left(\mu+\frac{\mu_{t}}{\sigma_{\varepsilon}}\right) \frac{\partial \varepsilon}{\partial x_{i}} n_{i} d A+\int_{V} C_{\varepsilon 1} \frac{\varepsilon}{k}\left(G_{k}+C_{\varepsilon 3} G_{b}\right)-C_{\varepsilon 2} \rho \frac{\varepsilon^{2}}{k}\right] d V
$$

The generation of turbulence due to buoyancy is given by

$$
G_{b}=\beta g_{i} \frac{\mu_{t}}{P r_{t}} \frac{\partial T}{\partial x_{i}}
$$

It can be seen from the transport equations for $k$ that turbulence kinetic energy tends to be augmented $\left(G_{b}>0\right)$ in unstable stratification. For stable stratification, buoyancy tends to suppress the turbulence $\left(G_{b}<0\right)$.

\subsection{Using the Change of the $k$ - $\varepsilon$ Model Constants}

The $k-\varepsilon$ model uses five constants in the transport equations, $C_{l \varepsilon}, C_{2 \varepsilon}, C_{\mu}, \sigma_{k}$, and $\sigma_{\varepsilon}: C_{\mu}$ is used to calculate eddy viscosity for the second term of the $\varepsilon$ equation.

$$
\mu_{t}=\rho C_{\mu} \frac{k^{2}}{\varepsilon}
$$

The standard values of these constants are the default values determined empirically when the $k$ - $\varepsilon$ model was first derived by Launder and Spalding [34]. Because the $k-\varepsilon$ model constants are empirically derived, constants modified to fit atmospheric boundary layer data give better results for wind energy research than the standard constants. Alinot and Masson [17] used wind farm data to optimize the $k-\varepsilon$ model for atmospheric flow. By extensive algebraic manipulation of the turbulence equations Alinot and Masson derived a set of $k-\varepsilon$ constants that produced more accurate results, the values of these constants are in the Table 1.

Table 1. $k$ - $\varepsilon$ turbulence model constants.

\begin{tabular}{llllll}
\hline $\boldsymbol{k}-\boldsymbol{\varepsilon} \quad$ Constant & $\mathbf{C}_{\varepsilon 1}$ & $\mathbf{C}_{\varepsilon 2}$ & $\mathbf{C}_{\boldsymbol{\mu}}$ & $\boldsymbol{\sigma}_{\boldsymbol{k}}$ & $\boldsymbol{\sigma}_{\varepsilon}$ \\
\hline Standard [34] & 1.44 & 1.92 & 0.09 & 1.0 & 1.3 \\
Alinot-Masson [17] & 1.176 & 1.92 & 0.03329 & 1.0 & 1.3 \\
\hline
\end{tabular}

Other values of the modified model constants for more applications are available in the literature [35].

\section{Boundary Conditions}

In order to validate the proposed methodology, suitable velocity inlet was used which is similar to the experimental study $(u=25.5 \mathrm{~m} / \mathrm{s})$. Standard representation of the velocity profile in the ABL is as shown in Table 2.

Table 2. Inlet boundary conditions.

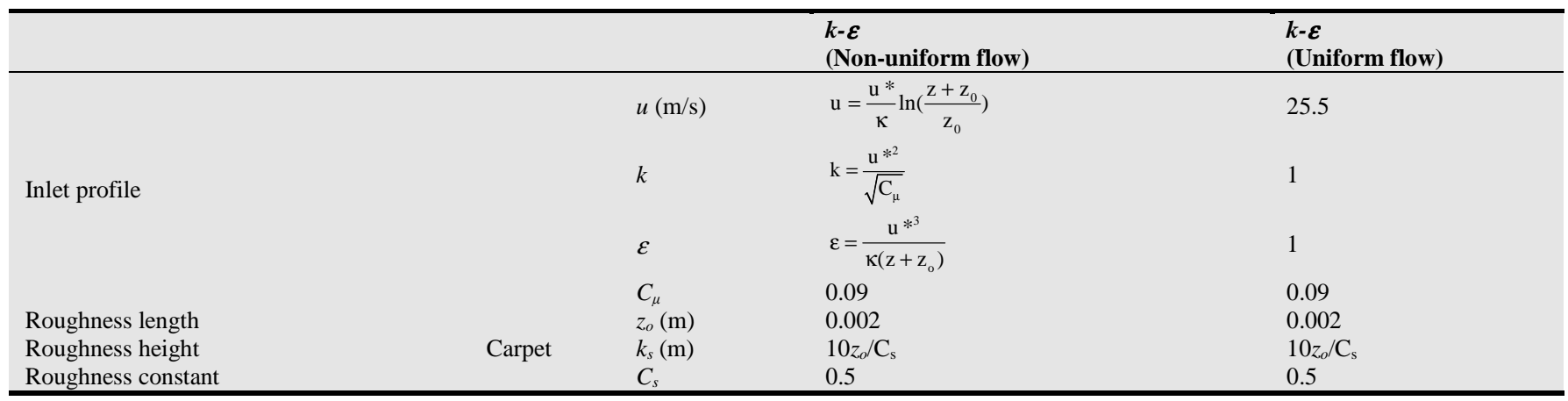

\section{Mesh Considerations}

\section{1 physical Domain}

According to [4], the domain represents a rectangular wind tunnel test section with dimensions $0.41 \times 0.41 \mathrm{~m}^{2}$ with a length of $1.8 \mathrm{~m}$, as shown in Fig. 1a. For initial adjustments, passive devices - screen and spires - were used and for fine tuning a wrinkled carpet were added as shown in Fig. $1 \mathrm{~b}$. Three types of screens ( $2 \mathrm{~mm}$ thick) with different meshes were used. (i) thin screen $\mathrm{KP}=1$, (ii) medium screen $\mathrm{KP}=$ 0.75 , and (iii) coarse screen $\mathrm{KP}=0.05$. The carpet used to form the ABL is $900 \mathrm{~mm}$ long with roughness of $3 \mathrm{~mm}$. Three spires, each with height of $307.7 \mathrm{~mm}$ and base width of 32.6 mm were used.

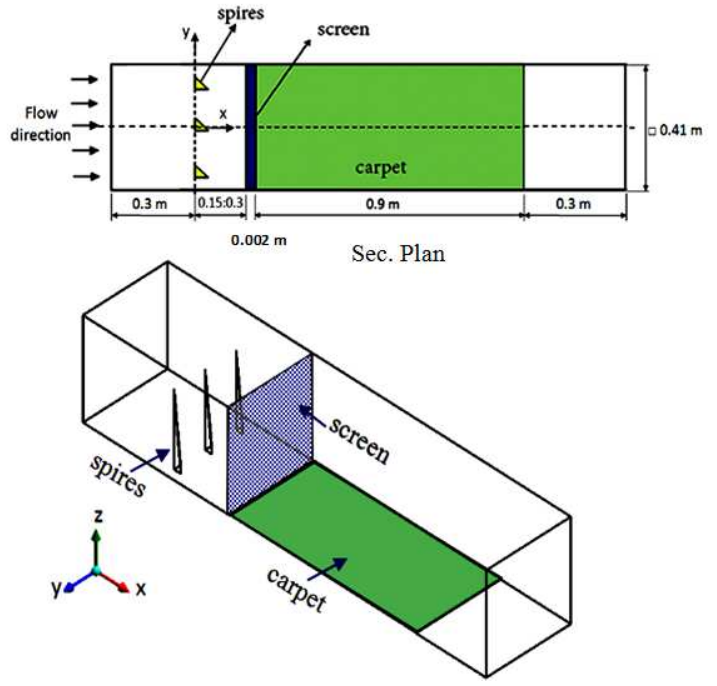

Fig 1a. Physical domain [4]. 


\subsection{Computational Domain}

The result of a numerical calculation is dependent on the mesh that is used. A too coarse mesh will give a high error in the result and as the mesh size gets finer this error should decrease. However, if the size of the mesh elements is small enough so that the numerical result is close to the real solution, a further decrease of the element size should not affect the solution significantly since the result is already correct. When this situation occurs the solution is said to be mesh-independent and this should always be achieved when performing a simulation. Mesh design (including the height of the first mesh cell) is critical to obtain a valid and accurate CFD solution, leading to very thin boundary layer. Factors to consider are mesh element shape, surface grid resolution, boundary layer resolution and the overall number of elements. Another requirement of first cell mesh height is that roughness elements can't be higher than the top of the cell. An unstructured Triangle grid was constructed based on refinements with a factor of 2 (397258 elements). The distance between the centre point of the wall-adjacent cells and the wall (carpet) is $0.002 \mathrm{~m}$. The inlet mean wind speed profile and the turbulence intensity profile are taken according to the experimental work [4]. Fig.1(b) shows the grid of the computational domain related to the physical domain [4] as shown in Fig.1(a).

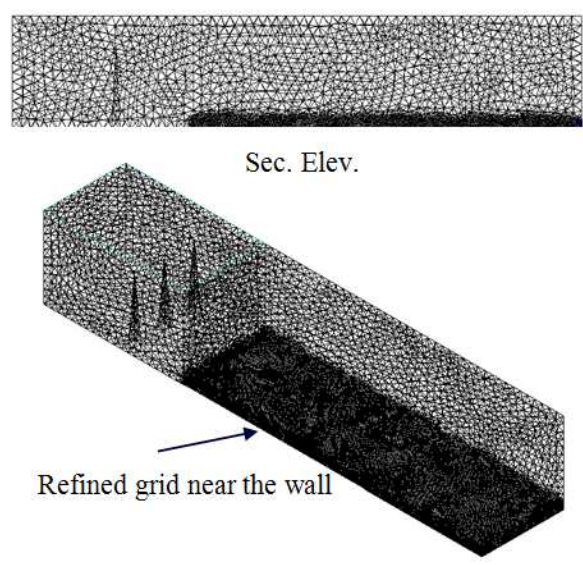

Fig 1b. Computational domain.

\subsection{Mesh Independency}

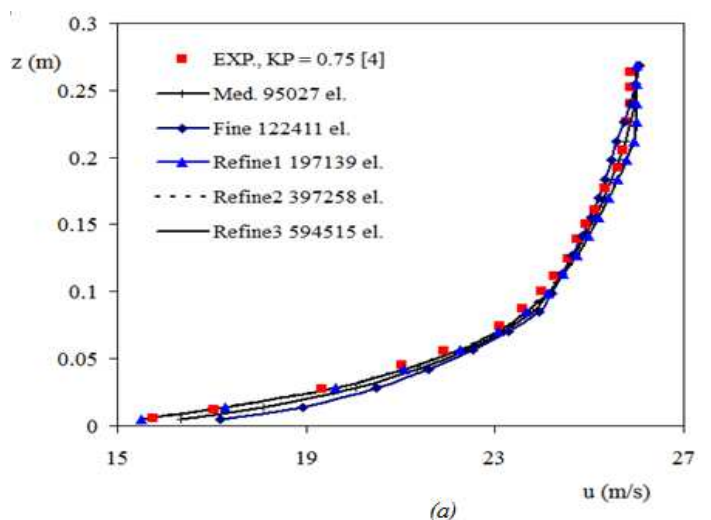

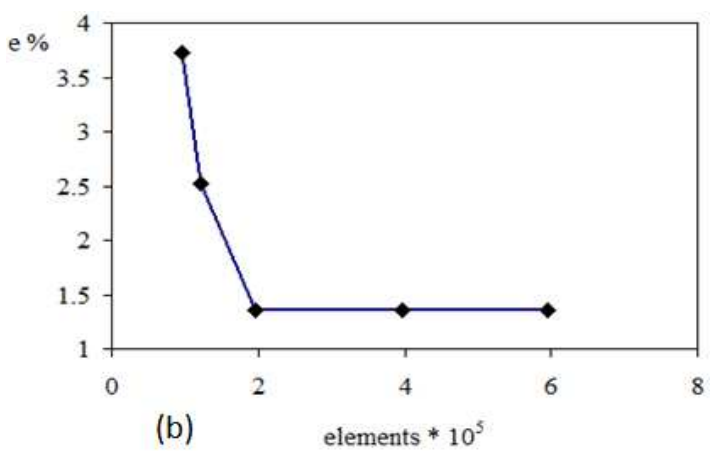

Fig 2. (a) Velocity profile (b) percentage error with different grid elements at $x$ $=1.42 \mathrm{~m}$.

Grid sensitivity study using velocity profile at $x=1.42 \mathrm{~m}$, non-uniform flow at inlet, $\mathrm{KP}=0.75$, and distance $0.3 \mathrm{~m}$ from experimental work [4] with different grid sizes as shown in Fig. 2(a).

The grid sensitivity study has led to acceptable grid sizes in the range of refinement 1 (197139 elements) up to refinement 3 (594515 elements), since within this range the velocity profile do not change appreciably as shown in Fig. 2(b).

\section{Results and Discussion}

In the present study, the predicted results from CFD simulations of the ABL are compared with experimental work [4] for fully developed at $x=1.42 \mathrm{~m}$.

The CFD simulations are carried out under different conditions of the different distance between spires and screen with different inlet profiles, the different turbulence models, the different pressure drop coefficient for screen, and different inlet boundary conditions.

Figures 3(a,c) show the wind-speed profile at $x=1.42 \mathrm{~m}$ for a medium screen $\mathrm{KP}=0.75$ positioned at $0.15 \mathrm{~m}$ and $0.3 \mathrm{~m}$ from the spires, at different inlet profiles. It can be seen that the predictive results, based on $k-\varepsilon$ turbulence model for non-uniform flow at inlet is very close with experimental. But, some discrepancies are noticeable for the case of uniform (constant) flow at inlet. On comparing the uniform and the non-uniform flow cases, the flow in the case of non-uniform flow enters the duct with imposed shear and hence the boundary layer grows in the downstream direction.

Figures 3(b,d) show the turbulent intensity at $x=1.42 \mathrm{~m}$ for a medium screen $\mathrm{KP}=0.75$ positioned at $0.15 \mathrm{~m}$ and $0.3 \mathrm{~m}$ from the spires, at different inlet profiles. It can be seen that the non-uniform flow at inlet is able to reproduce the experimental measurement in satisfactorily agreement compared in case of uniform flow at inlet.

Table 3 summarizes the outlet values of $\left(\tau_{w}, u^{*}, y^{+}, \delta\right.$, and $e \%)$ at different inlet profiles and different distances between spires and screen $(x=1.42 \mathrm{~m}$ and medium screen $\mathrm{KP}=0.75)$. The experimental results of the height of the ABL increased from 0.18 to 0.2 as the distance between the spires and the medium screen increased (from 0.15 to $0.3 \mathrm{~m}$ ). The computed boundary layer characteristics from the non-uniform flow at inlet for different distances between spires and screen show 
better agreement with results from the uniform flow at inlet, compared with the experimental results. Also, the percentage errors are decreased for non-uniform flow at inlet compared with the uniform flow, in particular for the case of non-uniform flow and distance is $0.3 \mathrm{~m}$ and percentage error (1.36). The boundary layer with spires, screen, and carpet is greater than 7.15 from without spires, screen, and carpet.
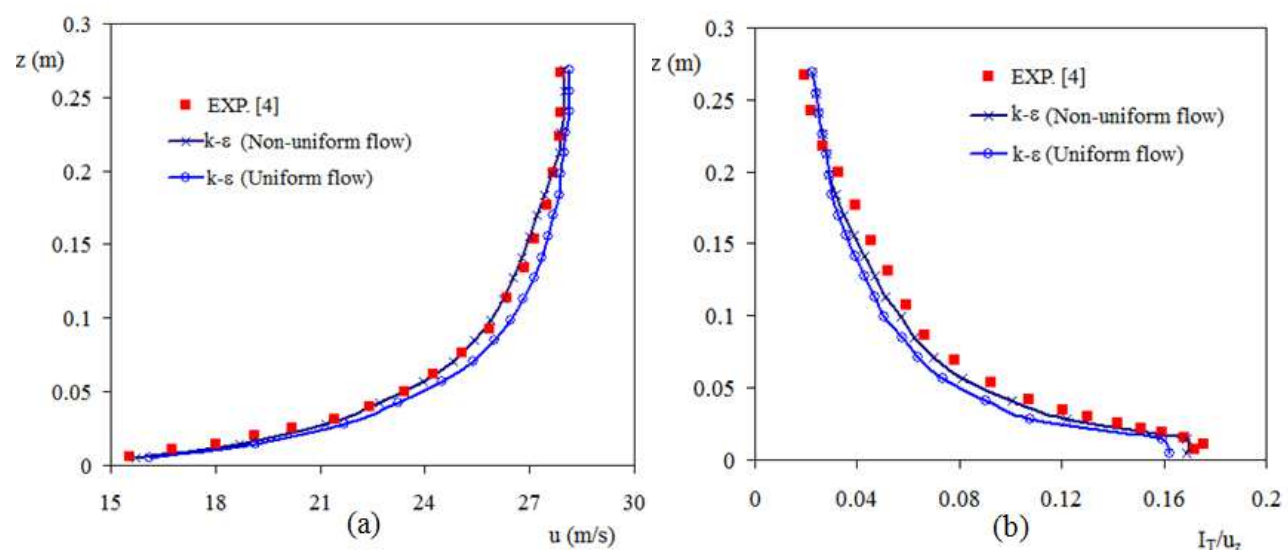

( $\mathrm{a}$ and $\mathrm{b}$ ) Distance between spires and screen $=0.15 \mathrm{~m}$.
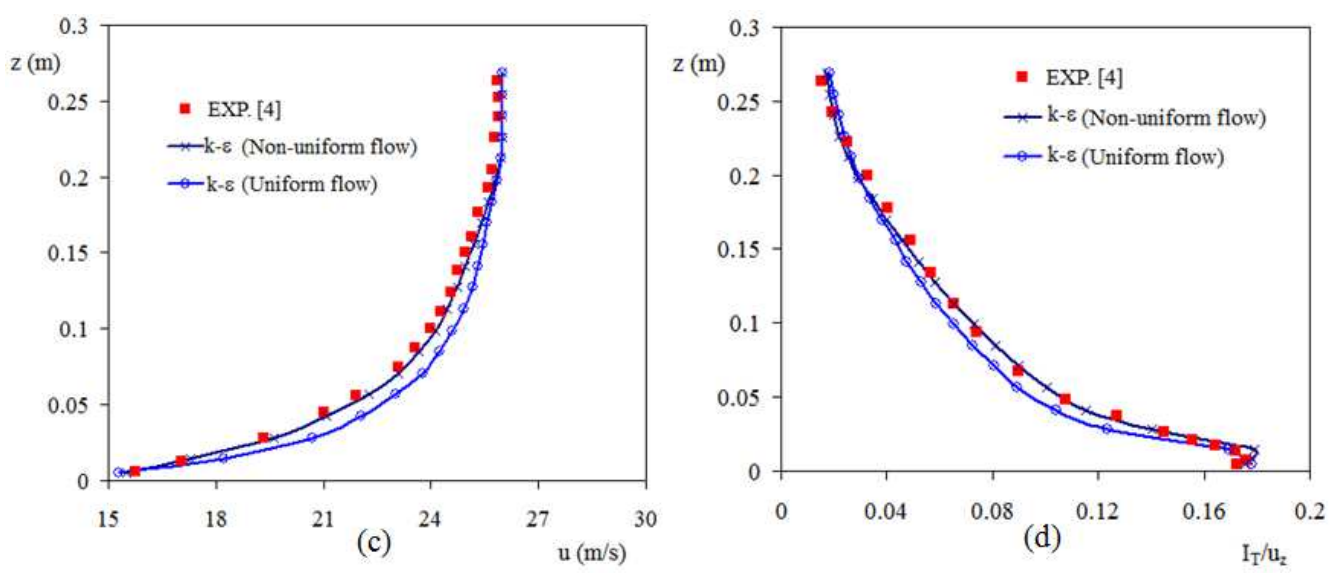

(c and d) Distance between spires and screen $=0.3 \mathrm{~m}$.

Fig 3. Velocity profile and turbulent intensity at different inlet profile $(x=1.42 \mathrm{~m}$, medium screen $(K P=0.75))$.

Table 3. Outlet conditions at different inlet profiles and different distance between spires and screen $(x=1.42 \mathrm{~m}$ and medium screen KP = 0.75$)$.

\begin{tabular}{|c|c|c|c|c|c|c|c|}
\hline \multirow{2}{*}{$\begin{array}{l}\text { Inlet profile } \\
\text { Distance between spires and screen (m) }\end{array}$} & & \multicolumn{2}{|c|}{ Non-uniform flow } & \multicolumn{2}{|c|}{ Uniform flow } & \multicolumn{2}{|c|}{ Exp. [4] } \\
\hline & & 0.15 & 0.3 & 0.15 & 0.3 & 0.15 & 0.3 \\
\hline Wall shear stress & $\tau_{w}\left(\mathrm{~N} / \mathrm{m}^{2}\right)$ & 0.99 & 0.99 & 1.04 & 0.95 & & \\
\hline Friction velocity & $u *(\mathrm{~m} / \mathrm{s})$ & 0.91 & 0.91 & 0.93 & 0.9 & & \\
\hline Wall function & $y^{+}$ & 340 & 340 & 348 & 335 & & \\
\hline $\begin{array}{l}\text { Boundary Layer thickness } \\
\text { without (spires, screen, carpet) }\end{array}$ & $\delta(\mathrm{m})$ & 0.028 & & 0.03 & & & \\
\hline Boundary Layer thickness & $\delta(\mathrm{m})$ & 0.179 & 0.199 & 0.176 & 0.197 & 0.18 & 0.2 \\
\hline Error \% & $e \%$ & 2.91 & 1.36 & 5.51 & 3.74 & & \\
\hline
\end{tabular}

Figures $4(a, b)$ indicate that the numerical solution based on $k-\varepsilon$ turbulence model for velocity contour and turbulent intensity at non-uniform flow at inlet, medium screen (KP = 0.75 ), and distant $0.3 \mathrm{~m}$ are capable of representing the experimental measurements in particular, in the $\mathrm{ABL}(x=1.42$ $\mathrm{m})$.

Figures 5(a,b) show the velocity profile and turbulent intensity at $x=1.42 \mathrm{~m}$ for a medium screen $\mathrm{KP}=0.75$ positioned at $0.3 \mathrm{~m}$ from the spires, at several turbulence models for non-uniform flow at inlet. It can be seen that the predictive results, based on $k-\varepsilon$ turbulence model are very close with experimental data [4] compared with other turbulence models. Figures $5(\mathrm{c}, \mathrm{d})$ show the boundary-layer thickness and percentage error. The boundary layer thickness for $k-\varepsilon$ turbulence model is greater than other turbulence models and the percentage error for $k-\varepsilon$ turbulence model is less than other turbulence models. From other hand, the predictive results (boundary layer thickness) using LES in short-chamber wind tunnel would be unexpected, despite its capability of representing the ABL for external flow applications. Therefore, it would be realistic not to be used for internal flow applications. However, the $k-\varepsilon$ model is 
considered to be suitable tool for generation of an ABL in short-chamber wind tunnel.

Figures $6(\mathrm{a}, \mathrm{b})$ show the velocity profile and turbulent intensity at $x=1.42 \mathrm{~m}$ for different pressure drop for screen positioned at $0.3 \mathrm{~m}$ from the spires, for non-uniform flow at inlet. It can be seen that the predictive results, based on $k-\varepsilon$ turbulence model for $\mathrm{KP}=0.75$ are very close with experimental measurements [4]. Figures 6(c,d) show the boundary-layer thickness and percentage error, the boundary layer thickness for $k-\varepsilon$ turbulence model for without screen $(\mathrm{KP}=0.0)$ is greater than other KP's. But, the percentage error for $k-\varepsilon$ turbulence model for $\mathrm{KP}=0.75$ is less than other KP's.

Figures $7(\mathrm{a}, \mathrm{b})$ show the velocity profile and turbulent intensity at $x=1.42 \mathrm{~m}$ for a medium screen $\mathrm{KP}=0.75$ positioned at $0.3 \mathrm{~m}$ from the spires, at different inlet boundary conditions for non-uniform flow at inlet. It can be seen that the predictive results, based on $k-\varepsilon$ turbulence model for all cases are in good agreement with experimental results. Figures $7(\mathrm{c}, \mathrm{d})$ show the boundary-layer thickness and percentage error, the boundary layer thickness for $k-\varepsilon$ turbulence model with $C_{\mu}=$ 0.033 and $k-\varepsilon$ turbulence model with buoyancy are equal to the

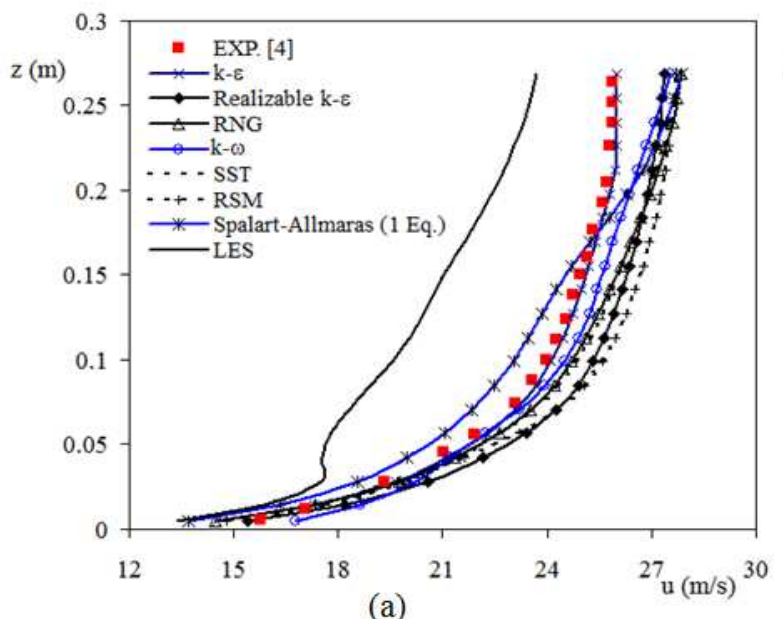

(a)

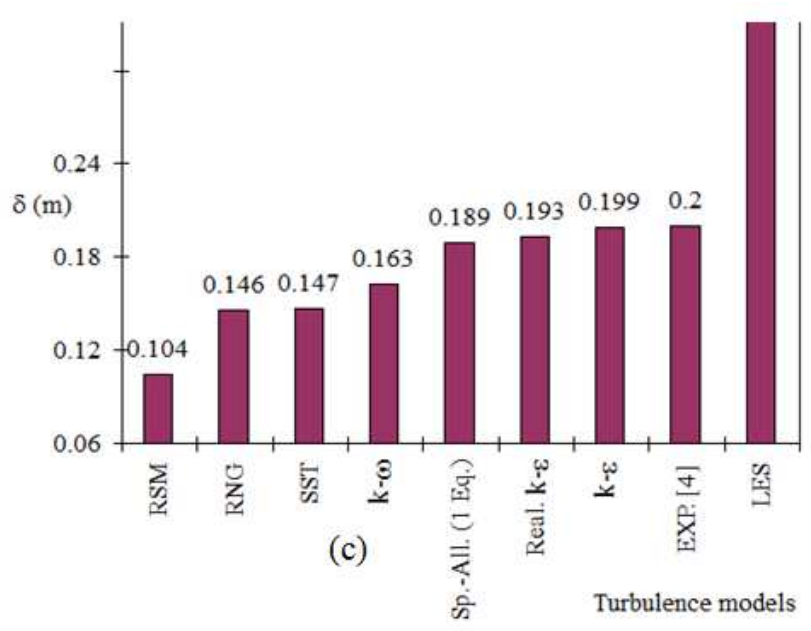

boundary-layer thickness for experimental result, and these cases are less than compared other cases.

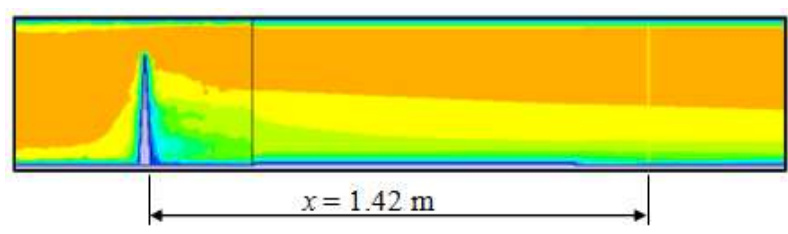

(a)
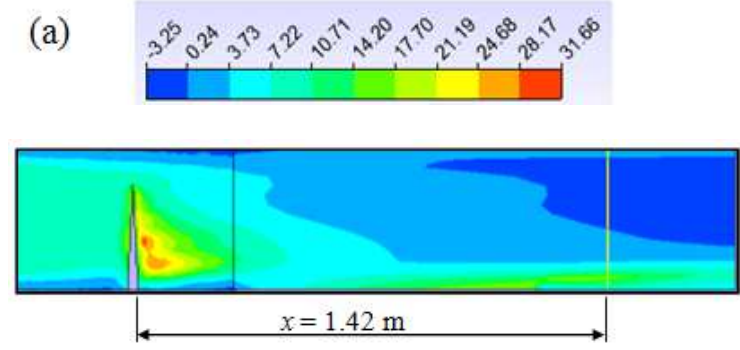

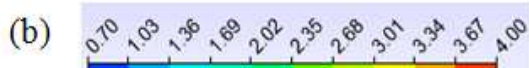

Fig 4. (a) Velocity contour (b) turbulent intensity at non-uniform flow, medium screen $(K P=0.75)$, and distance $0.3 \mathrm{~m}$.
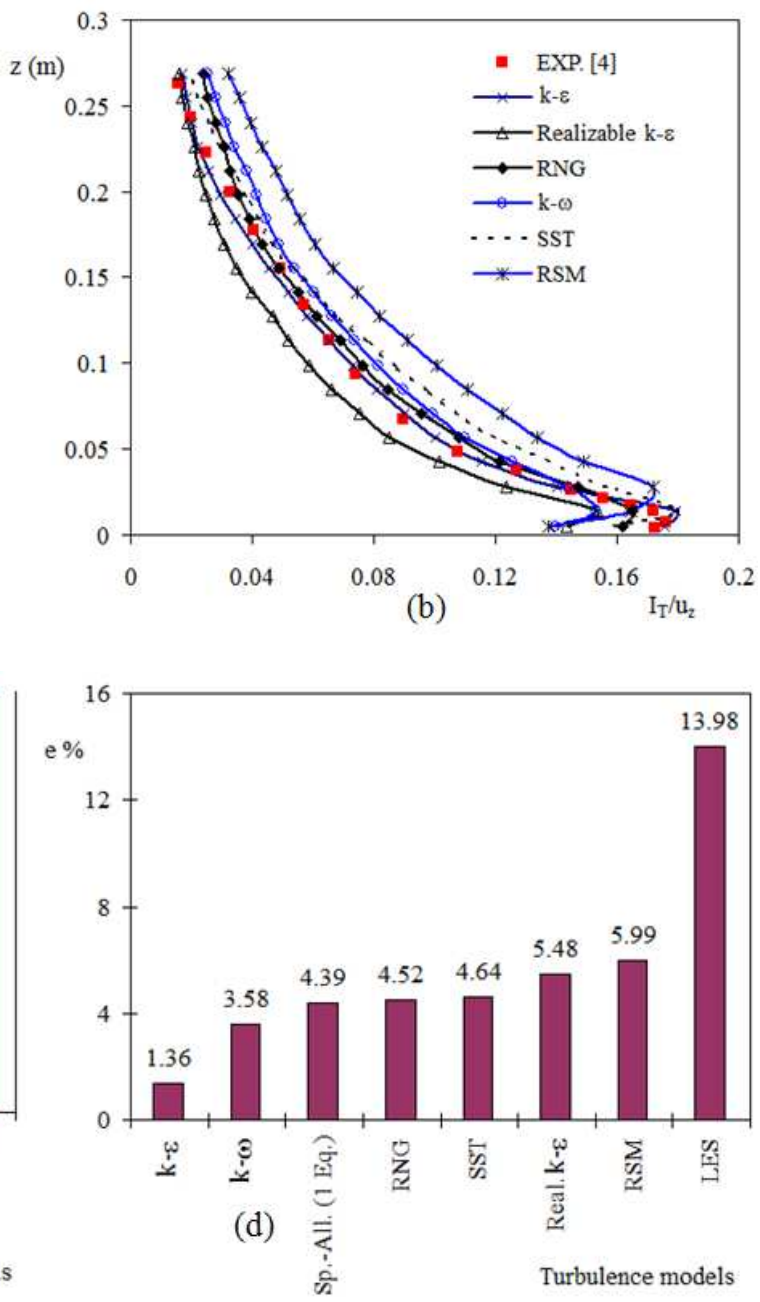

Fig 5. (a) Velocity profile (b) turbulent intensity (c) boundary layer thickness (d) percentage error at different turbulence models $(x=1.42 \mathrm{~m}$, medium screen (KP $=0.75$ ), distance $0.3 \mathrm{~m}$, for non-uniform flow at inlet). 

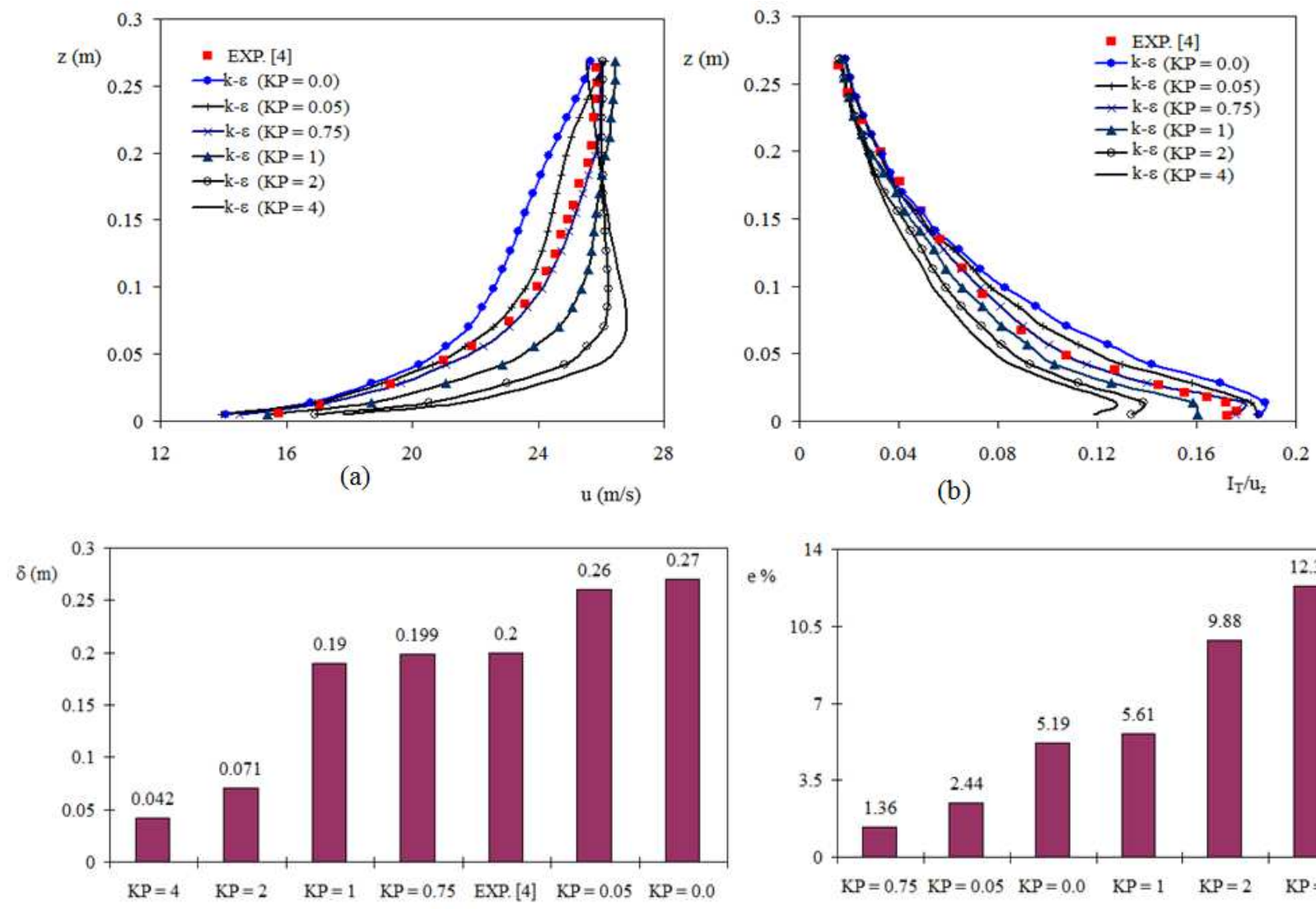

(c)

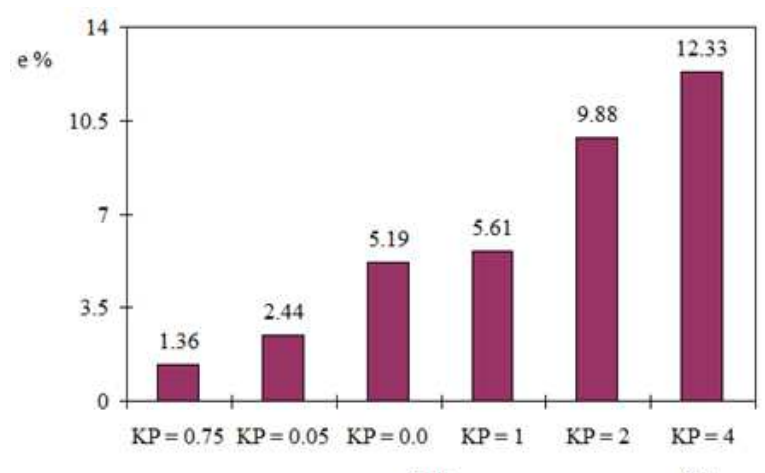

(d)

$\mathrm{KP}$

Fig 6. (a) Velocity profile (b) turbulent intensity (c) boundary layer thickness (d) percentage error at different pressure drop coefficient for screen $(x=1.42 \mathrm{~m}$, distance $0.3 \mathrm{~m}$, for non-uniform flow at inlet).

\section{Concluding Remarks}

In this study the following conclusions are drawn as follows:

- The $k-\varepsilon$ model is considered to be a suitable tool for generation of an ABL in short-section wind tunnel leading to reduce the tunnel operation time and cost during the actual experimentation phase.

- Mesh design is critical to obtain a valid and accurate CFD solution.

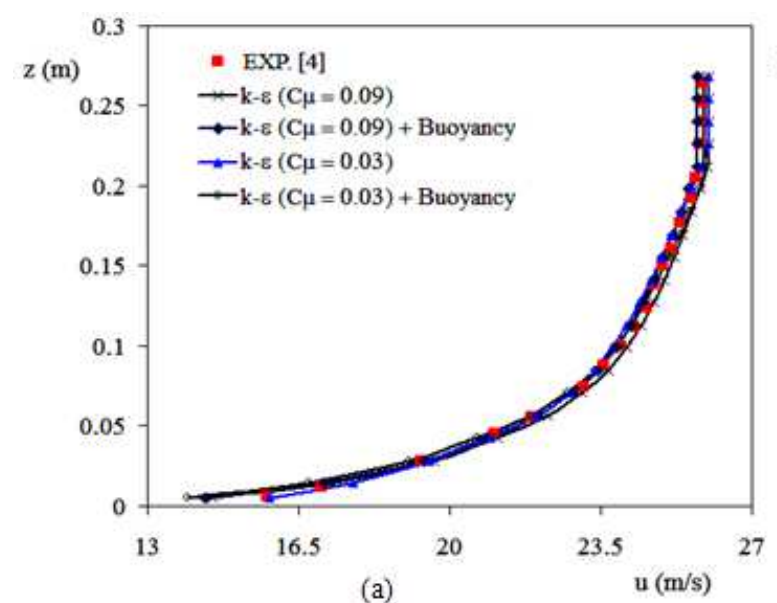

(a)
- Suitable boundary conditions that actually simulate the real flow are required.

- The predicted CFD values are very close to the corresponding experimental measurements.

- The influence of turbulence model constant $\left(C_{\mu}\right)$ and the buoyancy force makes significant changes to the flow without a major impact on computation time.

- The dimensionless wall distance $y+$ in the required range is crucial for the consistent and accurate application.

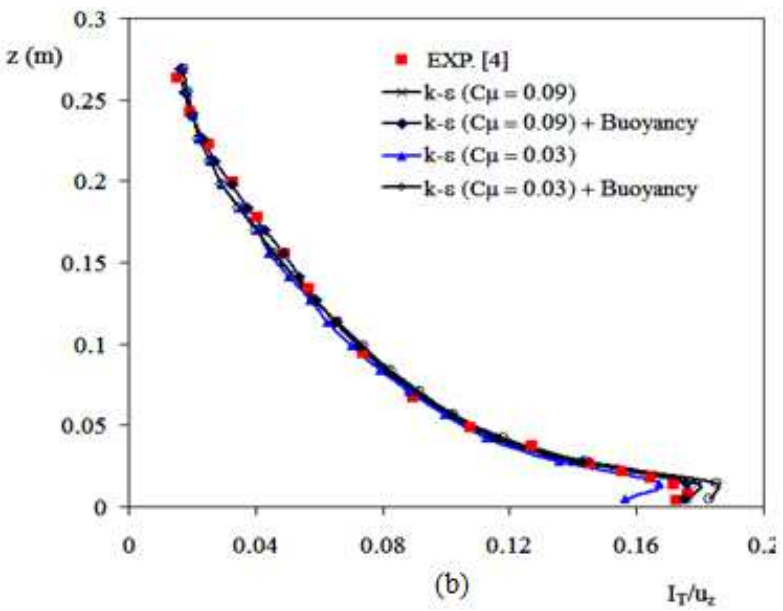




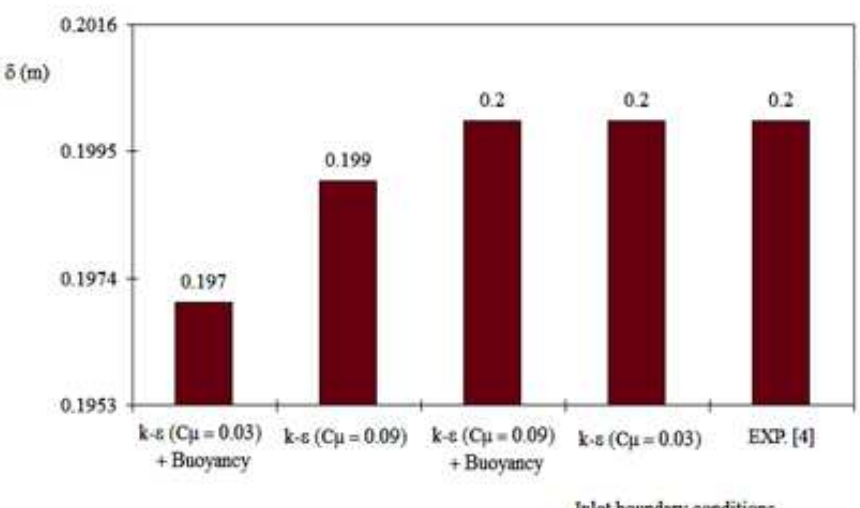

(c)

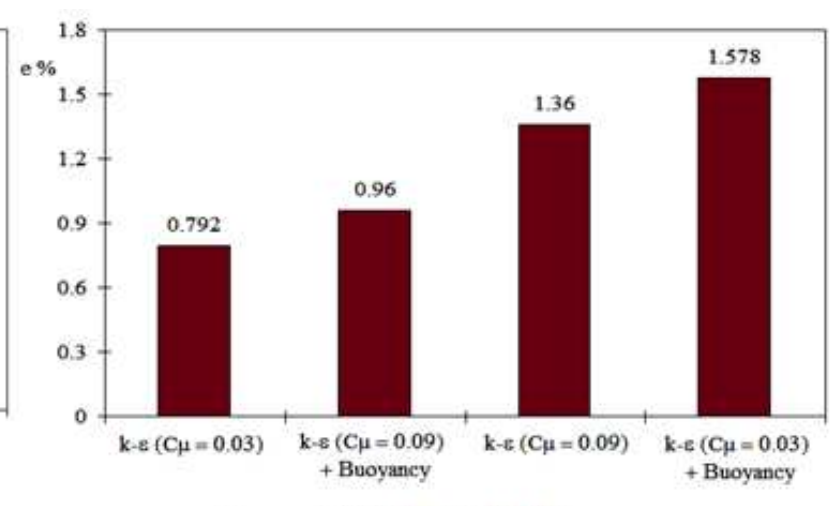

(d)

Fig 7. (a) Velocity profile (b) turbulent intensity (c) boundary layer thickness (d) percentage error at different inlet boundary conditions $(x=1.42 \mathrm{~m}$, medium screen $(K P=0.75)$, distance $0.3 \mathrm{~m}$, and non-uniform flow at inlet $)$.

\section{Nomenclature}

$\mathrm{C}_{\mathrm{s}} \quad$ Roughness constant $=0.5$

$\mathrm{C}_{\mu} \quad \mathrm{k}-\varepsilon$ turbulence model constant

$\mathrm{C}_{\varepsilon 1} \quad \mathrm{k}-\varepsilon$ turbulence model constant

$\mathrm{C}_{\varepsilon 2} \quad \mathrm{k}-\varepsilon$ turbulence model constant

$\mathrm{C}_{\varepsilon 3} \quad \mathrm{k}-\varepsilon$ turbulence model constant

e \% Percentage error, $\frac{1}{n} \sum_{1}^{n} \frac{u_{E X P .} u_{C F D}}{u_{E X P .}} \mid \times 100$

$\mathrm{G}_{\mathrm{b}} \quad$ Buoyant production of turbulence

$\mathrm{G}_{\mathrm{k}} \quad$ Shear production of turbulence

g Gravitational acceleration, $\mathrm{m}^{2} / \mathrm{s}$

$\mathrm{I}_{\mathrm{T}} \quad$ Turbulent intensity

k Turbulent kinetic energy

KP Pressure-drop coefficient $=\Delta \mathrm{P} / 0.5 \mathrm{pu}^{2}$

$\mathrm{k}_{\mathrm{s}} \quad$ Equivalent wall roughness height, $\approx 10 \mathrm{z}_{\mathrm{o}} / \mathrm{C}_{\mathrm{s}}, \mathrm{m}$

$\mathrm{Pr}_{\mathrm{t}} \quad$ Turbulent Prandtl number $=0.85$

$\operatorname{Re} \quad$ Reynolds number $=u L / v$

$\mathrm{u} \quad$ Mean velocity, $\mathrm{m} / \mathrm{s}$

$\mathrm{u}_{\mathrm{z}} \quad$ Vertical velocity, $\mathrm{m} / \mathrm{s}$

$\mathrm{u}^{*} \quad$ Friction velocity ratio $=\sqrt{ }_{\tau_{\mathrm{w}}} / \rho, \mathrm{m} / \mathrm{s}$

$\mathrm{y}^{+} \quad$ Dimensionless wall distance $=\mathrm{z} \cdot \mathrm{u} * / \mathrm{v}$

$\mathrm{Y}_{\mathrm{m}} \quad$ Turbulence production due to compressibility

$\mathrm{z} \quad$ Vertical coordinate

$\mathrm{z}_{\mathrm{o}} \quad$ Roughness length, $\mathrm{m}$

$z_{p} \quad$ Height of first cell centroid above wall, $m$

$\Delta \mathrm{P} \quad$ Static Pressure drop across the screen, $\mathrm{N} / \mathrm{m}^{2}$

$\alpha \quad$ Power law exponents $=1 / 7$

$\beta \quad$ Thermal coefficient

$\delta \quad$ Boundary Layer thickness, $\mathrm{m}$

$\varepsilon \quad$ Turbulent kinetic energy dissipation rate

$\kappa \quad$ von Karman constant, $\approx 0.41$

$\rho \quad$ Air density, $\mathrm{kg} / \mathrm{m}^{3}$

$\sigma_{\mathrm{k}} \quad \mathrm{k}-\varepsilon$ turbulence model constant

$\sigma_{\varepsilon} \quad \mathrm{k}-\varepsilon$ turbulence model constant

$\tau_{\mathrm{w}} \quad$ Wall shear stress, $\mathrm{N} / \mathrm{m}^{2}$

$\mu \quad$ Laminar fluid viscosity, $\mathrm{kg} / \mathrm{ms}$

$\mu_{\mathrm{t}} \quad$ Turbulent fluid viscosity, $\mathrm{kg} / \mathrm{ms}$

$v \quad$ Kinematic viscosity, $\mathrm{m}^{2} / \mathrm{s}$

\section{References}

[1] Jensen, M. and Franck, N., "Model Scale Tests in Turbulent Wind”, Part I, Danish Technical Press, Copenhagen, 1963.

[2] Jensen, M. and Franck, N., "Model Scale Tests in Turbulent Wind”, Part II, Danish Technical Press, Copenhagen, 1965.

[3] Blessmann, J., "Simulation of the Natural Wind Structure in an Aerodynamic Wind Tunnel" (in Portuguese), Ph.D. thesis, Instituto Tecnológico de Aeronáutica (ITA), S.P., Brazil, 169 p, 1973.

[4] Pires, L.B., Paula, I.B., Fisch, G., Gielow, R., and Girardi, R.,M., "Simulations of the Atmospheric Boundary Layer in a Wind Tunnel with Short Test Section" , J. Aerosp. Technol. Manag., Vol. 5, No. 3, pp. 305-314, 2013.

[5] Novak, M.D., Warland, J.S., Orchansky, A.L., Ketler, R. and Green, S., "Wind Tunnel and Field Measurements of Turbulent Flow in Forests. Part I: Uniformly Thinned Stands", Boundary Layer Meteorology, Vol. 95, pp. 457-495, 2000.

[6] Kwon, K.J., Lee, J.Y. and Sung, B., "PIV Measurements on the Boundary Layer Flow around Naro Space Center", Proceedings of the 5th International Symposium on Particle Image Velocimetry, pp. 22-24, 2003.

[7] Cao, S. and Tamura, T., "Experimental Study on Roughness Effects on Turbulent Boundary Layer Flow over a Two-Dimensional Steep Hill", Journal of Wind Engineering and Industrial Aerodynamics, Vol. 94, pp. 1-19, 2006.

[8] Kozmar, H., "Scale Effects in Wind Tunnel Modeling of an Urban Atmospheric Boundary Layer", Theoretical and Applied Climatology, Vol. 100, pp.153-162, 2009.

[9] Avelar, A.C., Brasileiro, F., Marto, A.G., Marciotto, E. and Fisch, G., "Wind Tunnel Simulation of the Atmospheric Boundary Layer for Study of the Wind Pattern at the Alcantara Space Center", J. Aerosp. Technol. Manag., Vol. 4, No. 4, 2012.

[10] Gorlé C., Van Beeck J., Rambaud P., and Van Tendeloo G., "CFD modelling of small particle dispersion: The influence of the turbulence kinetic energy in the atmospheric boundary layer", Elsevier Ltd., Atmospheric Environment 43, pp. 673-681, 2009. 
[11] Leitl, B., Kastner-Klein, P., Rau, M., and Meroney, R.N., "Concentration and flow distributions in the vincinity of u-shaped buildings: wind-tunnel and computational data", J. of Wind Eng. and Ind. Aerody. 67-68, 745-755, 1997.

[12] Chang, C., and Meroney, R., "Concentration and flow distributions in urban street canyons: wind tunnel and computational data", J. of Wind Eng. and Ind. Aerody., 91, 1141-1154, 2003.

[13] Yang, W., Jin, X., Jin, H., Gu, M., and Chen, S., "Application of new inflow boundary conditions for modeling equilibrium atmosphere boundary layer in rans-based turbulence models", In: Proceedings of International Conference on Wind Engineering 2007.

[14] Garcia Sagrado, A., van Beeck, J., Rambaud, P., and Olivari, D., "Numerical and experimental modelling of pollutant dispersion in a street canyon", J. of Wind Eng. and Industrial Aerodynamics 90, 321-339, 2002.

[15] Dixon, N., Boddy, J., Smalley, R., and Tomlin, A.S., "Evaluation of a turbulent flow and dispersion model in a typical street canyon in York", UK. Atmospheric Environment 40, 958-972, 2006.

[16] Pieterse J., E., "CFD Investigation of the Atmospheric Boundary Layer under Different Thermal Stability Conditions", Thesis, MSc., Stellenbosch University, 2013.

[17] Alinot, C. \& Masson, C., "Aerodynamic Simulations of Wind Turbines Operating in Atmospheric Boundary Layer With Various Thermal Stratifications", ASME Conference Proceedings, vol. 2002, no. 7476X, pp. 206-215, 2002.

[18] Blocken, B., Carmeliet, J. and Stathopoulos, T., "CFD Evaluation of Wind Speed Conditions in Passages Between Parallel Buildings- Effect of Wall-Function Roughness Modifications for the Atmospheric Boundary Layer Flow", Journal of Wind Engineering and Industrial Aerodynamics, vol. 95, no. 9-11, pp. 941-962, 2007a.

[19] Blocken, B., Stathopoulos, T. and Carmeliet, J., "CFD Simulation of the Atmospheric Boundary Layer: Wall Function Problems", Atmospheric Environment, vol. 41, no. 2, pp. 238-252, $2007 \mathrm{~b}$.

[20] Hargreaves, D. \& Wright, N., "On the Use of the k- $-\varepsilon$ Model in Commercial CFD Software to Model the Neutral Atmospheric Boundary Layer", Journal of Wind Engineering and Industrial Aerodynamics, vol. 95, no. 5, pp. 355-369, 2007.

[21] Fang, P., Gu M., Tan, J., Zhao, B. and Shao, D., "Modeling the Neutral Atmospheric Boundary Layer Based on the Standard k $-\varepsilon$ Turbulent Model: Modified Wall Function", The Seventh Asia-Pacific Conference on Wind Engineering, Taipei, Taiwan, 2009.
[22] Versteeg, H.K. and Malalasekera, W., "An Introduction to Computational Fluid Dynamics: the Finite Volume Method", Prentice Hall, Malaysia, 2007.

[23] ANSYS, Inc., "ANSYS FLUENT, Release 14.0: Installation and User's Guide", SAS IP, Inc., 2013.

[24] Roy, A.K., Babu, N., Bhargava, P.K., "Atmospheric Boundary Layer Airflow theough CFD Simulation on Pyramidal Roof of Square Plan Shape Buildings", VI National Conference on Wind Engineering, 2012.

[25] Rados, K.G., Prospathopoulos, J.M., Stefanatos, N.Ch., Politis, E.S., Chaviaropoulos, P.K. , and Zervos, A., " CFD modeling issues of wind turbine wakes under stable atmospheric conditions", EWEC '09 Proceedings, Marseille, 2009.

[26] Yang, W., Quan, Y., Jin, X., Tamura, Y. and Gu, M., "Influences of Equilibrium Atmosphere Boundary Layer and Turbulence Parameter on Wind Loads of Low-rise Buildings", J. of Wind Eng. and Ind. Aerody., vol. 96, no. 10, pp. 2080-2092, 2008.

[27] Liu, B., Qu, J., Zhang, W. and Qian, G., "Numerical Simulation of Wind Flow over Transverse and Pyramid Dunes", Journal of Wind Engineering and Industrial Aerodynamics, vol. 99, no. 8, pp. 879-888, 2011.

[28] Joubert, E.C., Harms, T.M., Muller, A., Hipondoka, M. and Henschel, J.R., "A CFD Study of Wind Patterns over a Desert Dune and the Effect on Seed Dispersion", Environmental Fluid Mechanics, vol. 12, no. 1, pp. 23-44, 2012.

[29] Alinot, C. \& Masson, C., "k- $\varepsilon$ Model for the Atmospheric Boundary Layer Under Various Thermal Stratifications", Journal of Solar Energy Engineering, vol. 127, no. 4, pp. 438443,2005 .

[30] White, F.M., "Viscous Fluid Flow", McGraw-Hill, New York, 1991.

[31] Richards P., Hoxey R., "Appropriate boundary conditions for computational wind engineering models using the $k-\varepsilon$ turbulence model", J. of Wind Eng. and Industrial Aerodynamics, 46,47, 145-153, 1993.

[32] Wilcox D., "Turbulence modelling for CFD", DCW Industries, California, 1993.

[33] Richards P., Norris S., "Appropriate boundary conditions for computational wind engineering models revisited", J. of Wind Eng. and Indus. Aerody., 99, 257-266, 2011.

[34] Launder, B.E. and Spalding, D. , "The Numerical Computation of Turbulent Flows", Computer Methods in Applied Mechanics and Engineering, vol. 3, no. 2, pp. 269-289, 1974.

[35] Sumner, J., Sibuet, Ch. W., and Masson, Ch., "CFD in Wind Energy: The Virtual, Multiscale Wind Tunnel", Energies, 3, 989-1013, 2010. 